\title{
PREVALENCE OF FATIGUE AND IMPACT ON QUALITY OF LIFE IN CASTRATION- RESISTANT PROSTATE CANCER PATIENTS: the VITAL study
}

\author{
A. Rodríguez Antolín ${ }^{1}$, L. Martínez-Piñeiro², M. E. Jiménez Romero³, J. B. García Ramos , D. López Bellido ${ }^{5}$ \\ J. Muñoz del Toro ${ }^{6 *}$, A. García García-Porrero ${ }^{6}$ and F. Gómez Veiga ${ }^{7}$
}

\begin{abstract}
Background: Fatigue is one of the most prevalent symptoms among cancer patients. Specifically, in metastatic castration-resistant prostate cancer (mCRPC) patients, fatigue is the most common adverse event associated with current treatments. The purpose of this study is to describe the prevalence of fatigue and its impact on quality of life $(\mathrm{QOL})$ in patients with CRPC in routine clinical practice.
\end{abstract}

Methods: This was a cross-sectional, multicentre study. Male chemo-naïve adults with high-risk non-metastatic (M0) CRPC and metastatic (M1) CRPC (mCRPC) were eligible. Fatigue was measured using the Brief Fatigue Inventory (BFI) and QoL was assessed using the Functional Assessment of Cancer Therapy questionnaire for patients with prostate cancer (FACT-P) and the FACT-General (FACT-G) questionnaire. Data were analysed using Mann-Whitney or Kruskal-Wallis tests (non-parametric distribution), a T-test or an ANOVA (parametric distribution) and the Fisher or chi-squared tests (categorical variables).

Results: A total of 235 eligible patients were included in the study (74 [31.5\%] with M0; and 161 [68.5\%] with M1). Fatigue was present in $74 \%$, with $38.5 \%$ of patients reporting moderate-to-severe fatigue. Mean FACT-G and FACT-P overall scores were $77.6 \pm 16.3$ and $108.7 \pm 21.4$, respectively, with no differences between the CRPC MO and CRPC M1 subgroups. Fatigue intensity was associated with decreased FACT-G/P scores, with no differences between groups. Among $151 \mathrm{mCRPC}$ patients with available treatment data, those treated with abiraterone-prednisone $\geq 3$ months showed a significant reduction in fatigue intensity $(p=0.043)$ and interference $(p=0.04)$ compared to those on traditional hormone therapy $(\mathrm{HT})$. Patients on abiraterone-prednisone $\geq 3$ months showed significantly better FACT-G/P scores than patients on HT ( $p=0.046$ and 0.018 , respectively).

Conclusion: Our data show a high prevalence and intensity of fatigue and its impact on QoL in chemo-naïve CRPC patients. There is an association between greater fatigue and less QoL, irrespective of the presence or absence of metastasis. Chemo-naïve $\mathrm{mCRPC}$ patients receiving more than 3 months of abiraterone acetate plus prednisone showed an improvement of fatigue and QoL when compared to those on traditional HT.

Trial registration: Not applicable since it is not an interventional study.

Keywords: Fatigue, Castration-resistant prostate cancer, Quality of life, BFI questionnaire, FACT-P questionnaire

\footnotetext{
* Correspondence: jmunozde@its.jnj.com

${ }^{6}$ Janssen Medical Department, Paseo de las 12 estrellas 5-7, 28042 Madrid,

Spain

Full list of author information is available at the end of the article
}

(c) The Author(s). 2019 Open Access This article is distributed under the terms of the Creative Commons Attribution 4.0 International License (http://creativecommons.org/licenses/by/4.0/), which permits unrestricted use, distribution, and reproduction in any medium, provided you give appropriate credit to the original author(s) and the source, provide a link to the Creative Commons license, and indicate if changes were made. The Creative Commons Public Domain Dedication waiver (http://creativecommons.org/publicdomain/zero/1.0/) applies to the data made available in this article, unless otherwise stated. 


\section{Background}

Prostate cancer is the most frequent cancer among males in Europe [1]. In 2017, approximately 160.000 men will be diagnosed with prostate cancer adding to 3.3 million existing survivors [2].

Even though optimal disease control is achieved with androgen deprivation therapy (ADT), most patients will eventually progress and develop metastatic castration-resistant PC (mCRPC) [3], which is associated with poor prognosis.

Cancer-related fatigue is one of the most prevalent, distressing and anticipated symptoms experienced by patients across all tumours. It is not proportional to recent activity and it interferes with usual functioning [4]. In patients with mCRPC, fatigue is by far a dominant symptom of the disease and is the most common adverse event associated with treatments [5]. Manifestations include a sense of persistent physical, mental and/ or emotional tiredness [6], which can cause a significant impact on quality of life (QoL) [7].

New therapeutic options for men with mCRPC have been developed over the last few years [8], including therapies targeting the androgen receptor pathway. Abiraterone acetate, a new class of anti-androgen, inhibits the synthesis of testosterone in the adrenal glands, testes and the tumour microenvironment, leading to suppression of PC growth and tumour regression [9]. In patients with $\mathrm{mCRPC}$ having progressed after docetaxel chemotherapy, abiraterone acetate and prednisone is the only treatment to have shown clinically meaningful improvements in fatigue [10].

Surprisingly, no studies have been conducted to evaluate the presence of fatigue in CRPC patients. The aim of this study was to describe the prevalence of fatigue and its impact on QoL in patients with both chemo-naïve mCRPC and high-risk non-metastatic CRPC in routine clinical practice.

\section{Methods}

\section{Study design}

The VITAL Study was a cross-sectional study, carried out in 39 specialised urological clinics across Spain between January 2015 and September 2015. The study was conducted in accordance with the Declaration of Helsinki including all amendments, and was approved by the Ethics Committee of Hospital Universitario 12 de Octubre (Madrid, Spain) as ethical reference committee. All patients gave written informed consent before their inclusion in the study, and their treatment followed routine clinical guidelines.

\section{Study population}

Eligible patients included adult males with a histological diagnosis of high-risk non-metastatic CRPC (defined as prostate-specific antigen [PSA] doubling time [PSADT] $\leq 10$ months; M0) or mCRPC (defined by visceral metastases, distant lymph nodes, or presence of bone metastases;
M1). Patients who had participated in any investigational drug study or any expanded-access or named-patient program were excluded, as well as those who had been treated with chemotherapy previously.

\section{Sample size calculation}

According to different studies published, fatigue is present in more than $40 \%$ of oncologic patients, increasing up to almost $90 \%$ depending on the study cohort characteristics, such as age, pathology, disease stage, etc. [11]. According to these data, an incidence of fatigue of around 65\% was estimated in advanced prostate cancer patients. A total of 243 patients were needed in order to detect an incidence of fatigue of $65 \%$ with a $6 \%$ precision and a $95 \%$ confidence interval. Considering a losing rate of $5 \%$, it was necessary to include a total of 256 patients in the study.

\section{Variables}

Data were collected using self-report questionnaires and supplemented with clinical data from the patients' medical records.

Fatigue was measured using the Brief Fatigue Inventory (BFI), a standard and reliable instrument used to assess fatigue in patients with cancer. The BFI is a nine-item instrument, consisting of three items assessing present, usual and worst level of fatigue and six items concerning the interference of fatigue with general activity over the previous week [12]. 'Fatigue intensity' was defined as the score of the worst level of fatigue in the last $24 \mathrm{~h}$ (BFI item 3 ), on a $0-10$ scale, with 0 being 'No fatigue' and 10 being 'As bad as you can imagine'. Fatigue was classified as mild, moderate or severe based on the score for item 3 (1-4, 57 , or 8-10, respectively). 'Fatigue interference' was defined as the average score of all interference items (items 4A$4 \mathrm{~F}$ ), on a $0-10$ scale, with 0 being 'Does not interfere' and 10 being 'Completely interferes'. The global BFI score is the arithmetic mean of all nine items (score, 0-10). The correlation between the physicians' and the patients' perception of fatigue was also calculated.

QoL was assessed using the Functional Assessment of Cancer Therapy questionnaire for patients with prostate cancer (FACT-P), which has been validated to estimate QoL in men with PC [13]. This tool comprises the 27item FACT-General (FACT-G) questionnaire, which measures QoL in cancer patients, and a 12-item prostate cancer subscale, designed to measure QoL specifically in prostate cancer. The FACT-P questionnaire is scored by adding the subscales of the FACT-G plus the prostate cancer subscale to yield a comprehensive QoL score.

Further data were recorded from the patients' medical records and included lifestyle habits, analytical values, comorbidities, current treatment, and other factors that could be associated with fatigue (Table 3 ) . 


\section{Statistical considerations}

Descriptive analyses were used for the study variables.

The prevalence of fatigue was calculated as the proportion of patients suffering from fatigue (BFI item 3 score $>0$ ), with the relevant $95 \%$ confidence interval (CI). The concordance between the patients' and the physicians' perception of fatigue was examined using the kappa index ( $\mathrm{\kappa}$ : $<0.0$ poor, $0.0-0.20$ slight, $0.21-0.40$ fair, 0.41-0.60 moderate, $0.61-0.80$ substantial, 0.811.00 almost perfect) [14].

When inferential analyses were required, the MannWhitney or Kruskal-Wallis tests were used for variables not fitting a normal (or parametric) distribution. For variables fitting a normal (or parametric) distribution, a Ttest or an ANOVA were used. In contingency tables for categorical variables, the Fisher or chi-squared tests were used. All hypothesis tests were two-sided, with a significance level of 0.05 .

A logistic regression analysis was performed to evaluate the association between clinical characteristics and the presence of fatigue, based on those variables with a $p$-value $<0.2$ in the bivariate analyses.

Missing data were not imputed and were left as lost. Statistical analyses were performed using the Statistical Package for the Social Sciences (SPSS) software package version 18.0.

\section{Results}

\section{Patient characteristics}

A total of 254 patients were included in the study. Of these, 19 subjects were excluded due to screening failures. The final evaluable population comprised 235 patients, with 74 (31.5\%) in the M0 group and 161 (68.5\%) in the M1 group (Table 1). At inclusion, median age for the entire patient population was 75.1 (46.2-92.4) years, median PSA value was $17.8(6.8-43.3) \mathrm{ng} / \mathrm{dL}$, and $90.7 \%$ of patients had an ECOG performance status grade of 0 or 1 .

\section{Fatigue}

The prevalence of fatigue in the overall population was $74 \%$ (95\% CI, 67.9-79.4\%), with 38.5\% (95\% CI, 32.1-44.9\%) of patients reporting moderate-to-severe fatigue (Table 2). The prevalence of fatigue was independent of the presence of metastases $(75.3 \%$ in $\mathrm{M} 0$ versus $73.9 \%$ in $\mathrm{M} 1, p=0.817)$.

According to the physicians' perception of fatigue, all 235 patients were classified as having fatigue (88 [37.4\%]) or no fatigue (147 [62.6\%]). Regarding the patients' selfperception, there were $86(36.6 \%)$ subjects with fatigue and $149(63.4 \%)$ with no fatigue. When these two approaches were compared, 77 (32.8\%) subjects were classified as having fatigue and 138 (58.7\%) as no fatigue. Overall these two approaches showed an "almost perfect" concordance, with $\mathrm{K}=0.818$.

The bivariate and multivariate analyses revealed that respiratory and cardiovascular disorders were the only factors significantly associated with the presence of fatigue based on the response to the BFI item 3 score $>0$ (odds ratio [OR] 4.7 and 3.6, respectively; Table 3).

\section{QoL outcomes}

Mean FACT-G and FACT-P overall scores were $77.6 \pm$ 16.3 and $108.7 \pm 21.4$, respectively. We compared M0 to M1 for their overall score on the QoL questionnaires, finding that both groups showed similar levels of functional status. The mean FACT-G score was $77.5 \pm 17.0$ for M0 versus $77.6 \pm 16.0$ for M1 $(p=0.955)$ and the mean FACT-P score was $108.6 \pm 21.7$ for M0 versus $108.7 \pm 21.3$ for M1 $(p=0.966)$. The mean scores for the domains of the FACT-G and FACT-P scales per study groups are displayed in Fig. 1.

An association with fatigue intensity was seen across all QoL measures. Patients who reported greater fatigue intensity showed lower QoL, with worse mean FACT-G and FACT-P scores. This association was found to be independent of absence or presence of metastases (Table 4).

\section{Fatigue and QoL in mCRPC according to treatment}

Among all $161 \mathrm{mCRPC}$ patients, 151 had available treatment data: $75(50 \%)$ patients were receiving traditional hormone therapy (HT; mostly bicalutamide and flutamide given that during the recruitment of this study, no new anti-androgen drug such as apalutamide or enzalutamide was commercially available) and $76(50 \%)$ were on abiraterone-prednisone. These were in turn classified based on treatment duration: 33 (22\%) patients had been receiving treatment for $<3$ months and $43(28 \%)$ for $\geq 3$ months. Table 5 shows the comparison of fatigue and QoL outcomes across these three cohorts. Patients receiving abiraterone acetate plus prednisone $\geq 3$ months showed a significant reduction in median fatigue intensity $(2.0[0.0-9.0]$ versus $3.0[0.0-10.0] ; p=0.043)$ and median fatigue interference (1.8 [0.0-10.0] versus 2.7 $[0.0-9.0] ; \mathrm{p}=0.04)$ as compared to those on HT. The proportion of patients with clinically significant fatigue (BFI item 3 score $\geq 5$ ) was lower among patients with $\geq 3$ months of abiraterone acetate plus prednisone treatment than in those receiving HT (25.6\% versus $41.3 \%$ ), although this difference did not reach statistical significance. Significantly better median FACT-G and FACT-P scores were found in patients treated with abiraterone acetate plus prednisone for $\geq 3$ months in comparison to patients treated with HT (FACT-G: 77.0 [24.7-101.0] versus 83.0 [38.0-103.0], $p=0.046 ; \quad$ FACT-P: 108.3 [50.7-140.0] versus 117.0 [61.0-138.0], $p=0.018$ ).

\section{Discussion}

To the best of our knowledge, this is the first observational study in the setting of routine clinical practice that specifically evaluates self-reported fatigue and its impact 
Table 1 Clinical characteristics

\begin{tabular}{|c|c|c|c|}
\hline & $\begin{array}{l}\mathrm{MO} \\
(N=74)\end{array}$ & $\begin{array}{l}M 1 \\
(N=161)\end{array}$ & $\begin{array}{l}\text { Total } \\
(N=235)\end{array}$ \\
\hline Age (years), median (IQR) & $77.3(71.3-81.3)$ & $74.8(70.0-80.4)$ & $75.1(70.2-80.6)$ \\
\hline BMI $\left(\mathrm{kg} / \mathrm{m}^{2}\right)$, median (IQR) & $28.3(25.7-30.9)$ & $27.7(25.4-30.1)$ & $27.7(25.5-30.4)$ \\
\hline \multicolumn{4}{|l|}{ Gleason score at diagnosis, n (\%) } \\
\hline$\leq 7$ & $32(43.9)$ & $55(36.4)$ & $87(38.8)$ \\
\hline$>7$ & $41(56.2)$ & $96(63.6)$ & $137(61.2)$ \\
\hline \multicolumn{4}{|l|}{ ECOG performance status, $\mathrm{n}(\%)$} \\
\hline ECOG 0-1 & $66(89.2)$ & $147(91.9)$ & $213(91.0)$ \\
\hline ECOG 2-3 & $8(10.8)$ & $13(8.1)$ & $21(9.0)$ \\
\hline Locally advanced and metastatic disease at diagnosis, n (\%) & $7(9.6)$ & $63(39.9)$ & $70(30.3)$ \\
\hline Extension of the disease at present, $\mathrm{n}(\%)$ (multiple answers possible) & $17(24.3)$ & $161(100)$ & $178(75.7)$ \\
\hline Bone & $0(0)$ & $145(90.1)$ & $145(61.7)$ \\
\hline$\leq 5$ bone metastases & 0 & $70(48.3)$ & $70(29.8)$ \\
\hline$>5$ bone metastases & 0 & $75(51.7)$ & $75(31.9)$ \\
\hline Locoregional lymph nodes & $17(23.0)$ & $48(29.8)$ & $65(27.7)$ \\
\hline VDistant lymph nodes & $0(0)$ & $36(22.4)$ & $36(15.3)$ \\
\hline Visceral & $0(0)$ & $6(3.7)$ & $6(2.6)$ \\
\hline Lung & $0(0)$ & $2(33.3)$ & $2(33.3)$ \\
\hline Liver & $0(0)$ & $2(33.3)$ & $2(33.3)$ \\
\hline Multiple locations & $0(0)$ & $2(33.3)$ & $2(33.3)$ \\
\hline \multicolumn{4}{|l|}{ Concomitant disease, n (\%) (multiple answers possible) } \\
\hline Hypertension & $42(56.8)$ & $93(57.8)$ & $135(57.4)$ \\
\hline Diabetes mellitus & $19(25.7)$ & $34(21.1)$ & $53(22.6)$ \\
\hline Obesity & $19(25.7)$ & $31(19.3)$ & $50(21.3)$ \\
\hline Cardiovascular disease & $17(23.0)$ & $32(19.9)$ & $49(20.9)$ \\
\hline Respiratory disorders & $12(16.2)$ & $20(12.4)$ & $32(13.6)$ \\
\hline Anaemia & $7(9.5)$ & $17(10.6)$ & $24(10.2)$ \\
\hline Depression & $6(8.1)$ & $8(5.0)$ & $14(6.0)$ \\
\hline \multicolumn{4}{|l|}{ Laboratory parameters, median (IQR) } \\
\hline PSA (ng/ml) & $11.9(7.1-30.2)$ & $24.2(6.6-63.8)$ & $17.8(6.8-43.3)$ \\
\hline Testosterone (ng/dl) & $0.3(0.1-12)$ & $0.3(0.1-2.5)$ & $0.3(0.1-5.4)$ \\
\hline $\mathrm{Hb}(\mathrm{g} / \mathrm{dl})$ & $13.9(13-14.2)$ & $13.1(12-14)$ & $13.4(12.2-14.2)$ \\
\hline $\mathrm{LDH}(\mathrm{UI} / \mathrm{I})$ & 209 (181.3-371.5) & $217.5(173.8-323.5)$ & $216(178.3-349.8)$ \\
\hline Alkaline phosphatase (UI/I) & $77.1(58-104)$ & $105(75.8-176.8)$ & $94(70-147)$ \\
\hline
\end{tabular}

$B M I$ Body mass index, $H b$ Haemoglobin, IQR Interquartile range, $L D H$ Lactate dehydrogenase, PSA Prostate-specific antigen

Table 2 Prevalence of fatigue

\begin{tabular}{|c|c|c|c|}
\hline & $\begin{array}{l}\mathrm{M0} \\
(\mathrm{N}=74)\end{array}$ & $\begin{array}{l}\mathrm{M1} \\
(\mathrm{N}=161)\end{array}$ & $\begin{array}{l}\text { Total } \\
(\mathrm{N}=235)^{*}\end{array}$ \\
\hline No fatigue (BFI questionnaire $=0$ ) & $18(24.7)$ & $42(26.1)$ & $60(25.6)$ \\
\hline Mild fatigue (BFI questionnaire $=1,2,3$ or 4 ) & $26(35.6)$ & $58(36.0)$ & $84(35.9)$ \\
\hline Moderate fatigue (BFI questionnaire $=5,6$ or 7 ) & $20(27.4)$ & $45(28.0)$ & $65(27.8)$ \\
\hline Severe fatigue (BFI questionnaire $=8,9$ or 10 ) & $9(12.3)$ & $16(9.9)$ & $25(10.7)$ \\
\hline
\end{tabular}


Table 3 Factors associated with fatigue

\begin{tabular}{|c|c|c|c|c|}
\hline & Bivariate & & Multivariate & \\
\hline & OR $(95 \% \mathrm{Cl})$ & $p$-value & $\mathrm{OR}(95 \% \mathrm{Cl})$ & $p$-value \\
\hline Age & $1.032(0.995-1.071)$ & 0.089 & - & - \\
\hline PSA & $1.001(0.999-1.003)$ & 0.464 & - & - \\
\hline Testosterone & $0.984(0.956-1.012)$ & 0.248 & - & - \\
\hline $\mathrm{Hb}$ & $0.821(0.666-1.012)$ & 0.065 & - & - \\
\hline $\mathrm{LDH}$ & 0.999 (0.996-1.003) & 0.680 & - & - \\
\hline ALP & $1.001(0.998-1.005)$ & 0.503 & - & - \\
\hline Albumin & $0.404(0.159-1.025)$ & 0.056 & - & \\
\hline Sodium & $0.889(0.782-1.010)$ & 0.071 & - & - \\
\hline Alcohol consumption & $2.750(0.793-9.542)$ & 0.111 & - & - \\
\hline Regular exercise & $0.550(0.294-1.031)$ & 0.062 & - & \\
\hline Diabetes mellitus & $1.918(0.873-4.212)$ & 0.105 & - & - \\
\hline Cardiovascular disorders & $4.884(1.676-14.233)$ & 0.004 & $4.7(1.6-13.9)$ & 0.005 \\
\hline Respiratory disorders & $3.800(1.113-12.969)$ & 0.033 & $3.6(1.0-12.5)$ & 0.043 \\
\hline High blood pressure & $1.522(0.843-2.746)$ & 0.163 & - & - \\
\hline Sleep disturbances & $3.982(0.503-31.511)$ & 0.191 & - & - \\
\hline Time since diagnosis & $1.054(0.981-1.132)$ & 0.150 & - & \\
\hline Surgical castration & $0.246(0.53-1.131)$ & 0.072 & - & - \\
\hline Chemical castration & $0.000(0.000-)$ & 1.000 & - & - \\
\hline Radical prostatectomy at diagnosis & $0.578(0.273-1.225)$ & 0.153 & - & - \\
\hline External radiation therapy at diagnosis & $1.747(0.792-3.851)$ & 0.167 & - & - \\
\hline Duration of previous LHRH therapy & & 0.757 & & \\
\hline $7-12$ months & $1.000(0.084-11.931)$ & 1.000 & - & - \\
\hline 13-18 months & $0.583(0.052-6.587)$ & 0.663 & - & - \\
\hline 19-24 months & $1.111(0.097-12.750)$ & 0.933 & - & - \\
\hline 25-35 months & $0.905(0.080-10.210)$ & 0.935 & - & - \\
\hline 36-47 months & $0.857(0.076-9.695)$ & 0.901 & - & - \\
\hline 48-59 months & $0.571(0.049-6.606)$ & 0.654 & - & - \\
\hline$\geq 60$ months & $1.333(0.131-13.586)$ & 0.808 & - & - \\
\hline Urinary catheter & $3.857(0.527-28.241)$ & 0.184 & - & - \\
\hline Haematuria & $4.370(0.556-34.346)$ & 0.161 & - & - \\
\hline
\end{tabular}

Cl Confidence interval, $\mathrm{Hb}$ Haemoglobin, $\mathrm{LDH}$ Lactate dehydrogenase, $L H R H$ Luteinizing hormone-releasing hormone, OR Odds ratio, PSA Prostate-specific antigen

on QoL in chemo-naïve patients with CRPC, using wellestablished validated instruments for this purpose.

Besides pain, fatigue is the most distressing and predominant symptom reported by patients with mCRPC [15]. We found that almost three quarters of our study population were suffering from fatigue, regardless of the presence of metastases, and a high proportion of patients were suffering from moderate-to-severe fatigue. The prevalence of fatigue has been studied previously, ranging from 39 to $90 \%$ [11]; however, the prevalence rates for cancer-related fatigue vary widely depending on how fatigue is defined and assessed.

Even though cancer-related fatigue has a terrible impact on daily activities and is one of the main drivers of poor QoL [16], a poor correlation has long been observed between clinician-perceived and patient-reported subjective symptoms, such as fatigue [17-19]. Surprisingly, in our study we observed an improvement in the level of agreement between the clinicians' and the patients' perception of fatigue, finding an excellent concordance between the two. This highlights the importance of the need for assessing fatigue symptoms on an ongoing basis and developing management plans to increase health-care provider awareness of early fatigue symptoms, in order to help patients and their primary carers to recognise fatigue symptoms early, and thereby increase QoL in this group of patients.

A list of possible correlates of fatigue in $\mathrm{MCRPC}$ was proposed recently by Colloca et al., grouping them in cancerrelated (anemia, pain, etc), patient-related (physical 


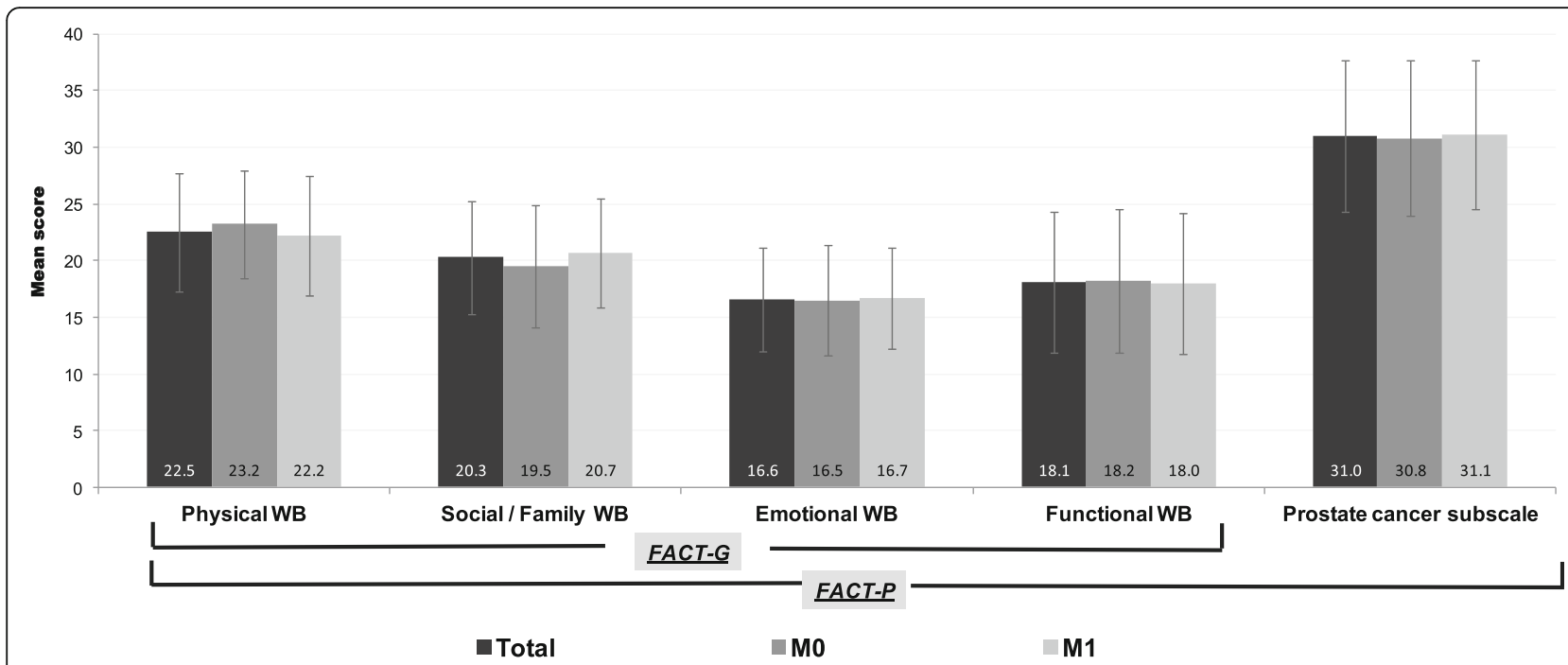

Fig. 1 Results of the FACT-G and FACT-P questionnaires per study groups

function, liver dysfunction, etc) and treatment-related (hormonal therapy, chemotherapy, etc) [5]. The logistic regression model developed in this study has revealed that beyond initial therapy or biological parameters, "patient-related" respiratory and cardiovascular disorders were the most important explanatory factors associated with fatigue. In bivariate analysis, hemoglobin and the practice of regular exercise seem to have some value but did not reach statistical significance. Interestingly, the time in treatment with analogues had no impact on fatigue in our study.

In this study, we found that PC patients showed similar levels of functionality, as measured by the FACT-P questionnaire, irrespective of the absence or presence of metastases. In light of previous studies, this was a rather unexpected finding, as the prevalence of cancer-related fatigue is likely to increase as the disease progresses [10, $20]$. We observed that fatigue intensity was directly related to impaired QoL across all dimensions of the FACT-G and FACT-P instruments. This is in line with previous studies, in which fatigue was the most common symptom and the most significant predictor of impaired QoL [21]. As a multidimensional symptom, fatigue can affect specific dimensions of the QoL instruments, for which measurement of intensity alone is rather inappropriate. The findings reported by Gupta et al. [22] have essential implications in clinical practice. The authors highlighted that patients with $\mathrm{PC}$ at close monitoring of QoL, coupled with an improvement in fatigue, dyspnea and cognitive function within 3 months of treatment, were at a significantly decreased risk of mortality.

Our findings are of practical importance to mCRPC treatment and further support abiraterone as a valuable option for the treatment of mCRPC patients. Sternberg et al. [10] reported the results of the first phase III clinical trial in the setting of advanced prostate cancer to specifically evaluate patient-reported fatigue outcomes, highlighting that abiraterone-prednisone was associated with improvements not only in fatigue intensity but also in fatigue interference, and that this was perceivable and meaningful to patients. The AQUARiUS study [23] also added evidence supporting the benefits of abiraterone-prednisone treatment regarding fatigue. In this observational study, fatigue and cognition was evaluated in mCRPC patients receiving either abiraterone-prednisone or enzalutamide. Abirateroneprednisone showed favourable effect on fatigue across all fatigue scales evaluated, proving significant difference at 3 months of treatment comparing to enzalutamide. In keeping with these, we have found that chemo-naïve mCRPC

Table 4 Interference of fatigue with QoL instruments in the study cohorts

\begin{tabular}{|c|c|c|c|c|c|c|}
\hline & \multicolumn{3}{|l|}{ FACT-G } & \multicolumn{3}{|l|}{ FACT-P } \\
\hline & $\overline{\mathrm{MO}}$ & M1 & Total & $\overline{\mathrm{MO}}$ & M1 & Total \\
\hline No fatigue & $91.1 \pm 11.8$ & $86.7 \pm 13.8$ & $88.0 \pm 13.3$ & $127.6 \pm 16.9$ & $122.1 \pm 16.8$ & $123.7 \pm 16.9$ \\
\hline Mild fatigue & $80.7 \pm 12.5$ & $78.6 \pm 13.2$ & $79.3 \pm 12.9$ & $111.1 \pm 14.8$ & $109.6 \pm 17.0$ & $110.1 \pm 16.3$ \\
\hline Moderate fatigue & $67.5 \pm 13.8$ & $73.3 \pm 14.9$ & $71.5 \pm 14.7$ & $96.5 \pm 15.9$ & $102.8 \pm 20.5$ & $100.8 \pm 19.3$ \\
\hline Severe fatigue & $65.7 \pm 21.8$ & $61.8 \pm 18.1$ & $63.2 \pm 19.2$ & $90.5 \pm 27.7$ & $86.2 \pm 24.3$ & $87.7 \pm 25.1$ \\
\hline$p$-value & $<0.001$ & $<0.001$ & $<0.001$ & $<0.001$ & $<0.001$ & $<0.001$ \\
\hline
\end{tabular}

Data are expressed as mean \pm SD 
Table 5 Comparison of Fatigue and QoL outcomes in MCRPC patients

\begin{tabular}{|c|c|c|c|c|c|c|}
\hline & $\begin{array}{l}\text { HT } \\
(n=75)\end{array}$ & AAP $<3$ months $(n=33)$ & AAP $\geq 3$ months $(n=43)$ & $p$-value & $\begin{array}{l}p \text {-value AAP } \geq 3 \text { months } \\
\text { vs AAP }<3 \text { months }\end{array}$ & $\begin{array}{l}p \text {-value } \\
\text { AAP } \geq 3 \text { months } \\
\text { vs HT }\end{array}$ \\
\hline $\begin{array}{l}\text { Fatigue intensity } \\
\text { (BFI item 3) }\end{array}$ & $3.0(0.0-10.0)$ & $4.0(0.0-8.0)$ & $2.0(0.0-9.0)$ & $0.125^{a}$ & 0.243 & 0.043 \\
\hline Fatigue severity, n (\%) & & & & 0.039 & - & - \\
\hline No fatigue & $15(20.0)$ & $10(30.3)$ & $13(30.2)$ & & & \\
\hline Mild fatigue & $29(38.7)$ & $8(24.2)$ & $19(44.2)$ & & & \\
\hline Moderate fatigue & $18(24.0)$ & $14(42.4)$ & $9(20.9)$ & & & \\
\hline Severe fatigue & $13(17.3)$ & $1(3.0)$ & $2(4.7)$ & & & \\
\hline $\begin{array}{l}\text { Interference (BFI } \\
\text { item 4A-4F) }\end{array}$ & $2.7(0.0-9.0)$ & $2.7(0.0-7.0)$ & $1.8(0.0-10.0)$ & $0.106^{\mathrm{b}}$ & 0.473 & 0.04 \\
\hline FACT-G overall score & $77.0(24.7-101.0)$ & $81.0(35.0-101.0)$ & $83.0(38.0-103.0)$ & $0.121^{c}$ & 0.429 & 0.046 \\
\hline FACT-P overall score & $108.3(50.7-140.0)$ & $114.3(57.0-137.0)$ & $117.0(61.0-138.0)$ & $0.052^{d}$ & 0.402 & 0.018 \\
\hline Physical WB & $22.0(4.0-28.0)$ & $24.0(12.0-28.0)$ & $24.0(9.0-28.0)$ & $0.031^{e}$ & 0.643 & 0.014 \\
\hline Social / Family WB & $21.0(3.0-28.0)$ & $21.0(2.0-28.0)$ & $20.0(11.0-28.0)$ & 0.834 & - & - \\
\hline Emotional WB & $17.0(3.0-24.0)$ & $17.0(7.0-23.0)$ & $18.0(7.0-23.0)$ & 0.727 & - & - \\
\hline Functional WB & $17.0(0.0-28.0)$ & $19.0(3.0-27.0)$ & $21.0(6.0-28.0)$ & $0.041^{f}$ & 0.054 & 0.017 \\
\hline Prostate cancer subscale & $30.0(11.0-42.0)$ & $32.0(17.0-43.0)$ & $34.0(20.0-43.0)$ & $0.029^{9}$ & 0.462 & 0.008 \\
\hline
\end{tabular}

Data are expressed as median (IQR), unless otherwise stated

$A A P$ Abiraterone Acetate-prednisone, $H T$ traditional hormone therapy, IQR interquartile range, WB well-being

patients receiving more than 3 months of treatment with abiraterone-prednisone had lower levels of fatigue and better QoL compared to traditional hormone therapy, which could not be ascribed to differences in previous chemotherapy exposure. Despite all these findings, we cannot determine the mechanism underlying the benefits associated with a longer duration of treatment with abirateroneprednisone, which could be the result of amelioration of disease progression. Nonetheless, these findings should guide new longitudinal studies to confirm the results.

The cross-sectional design is probably the most important limitation of our study. In common with all cross-sectional studies, we can only offer a 'snapshot' of the current situation. It may have been better to follow the patients throughout a longer period of time, but this would have taken much longer, and we probably would have needed to increase the sample size. It should also be noted that, as an observational study design, certain biases might have been introduced when collecting the data. These might affect the interpretation of the results. However, conducting this type of studies -in real life- is of great relevance, as they help us learn about the conditions derived from routine clinical practice.

\section{Conclusions}

Our data show high prevalence rates and high intensity of fatigue with a significant impact on QoL in high-risk M0 CRPC and chemo-naive mCRPC patients. There is an association between more fatigue and less QoL, which is independent of the presence or absence of metastases. Finally, chemo-naïve mCRPC patients receiving more than 3 months of abiraterone-prednisone showed an improvement of fatigue and QoL compared to patients on traditional HT.

\section{Supplementary information}

Supplementary information accompanies this paper at https://doi.org/10. 1186/s12894-019-0527-8.

Additional file 1. Participant Sites VITAL STUDY

\section{Abbreviations}

ADT: Androgen Deprivation Therapy; BFI: Brief Fatigue Inventory; CRPC: Castration Resistant Prostate Cancer; FACT-G: FACT-General; FACT$P$ : Functional Assessment of Cancer Therapy questionnaire for patients with prostate cancer; HT: Hormone Therapy; M0: Non-metastatic; M1: Metastatic; mCRPC: Metastatic Castration Resistant Prostate Cancer; PC: Prostate Cancer; PSA: Prostate Specific Antigen; PSADT: Prostate Specific Antigen Doubling Time; QoL: Quality of Life

\section{Acknowledgements}

The authors would like to acknowledge all investigators and participating centers for their valuable contributions. The authors would like to thank Ana López-Ballesteros and Antonio Torres-Ruiz at Dynamic Science S.L. for their medical writing and editorial support. The study was financially supported by Janssen.

\section{Authors' contributions}

ARA, LMP, AGG and FGV made substantial contributions to conception and design; JMT and AGG made substantial contribution to the analysis of data; JMT, AGG, ARA, LMP and FGV made substantial contribution to the interpretation of data; ARA, LMP, MEJ, JBG, DLB and FGV made substantial contributions to acquisition of data; ARA, LMP, MEJ, JBG, DLB, JMT, AGG and FGV have been involved in drafting the manuscript; all authors have been involved in revising the manuscript critically for important intellectual content; all authors have given final approval of the version to be published; all authors agreed to be accountable for all aspects of the work in ensuring that questions related to the accuracy or integrity of any part of the work 
are appropriately investigated and resolved. All authors read and approved the final manuscript.

\section{Funding}

This study was funded by Janssen Cilag S.A. Janssen-Cilag S.A. was involved in the design of the study, interpretation of data, and in writing the manuscript. Quality control and statistical analyses were performed by a contract research organization that was funded by Janssen-Cilag S.A..

\section{Availability of data and materials}

The datasets used and/or analysed during the current study are available from the corresponding author on reasonable request.

\section{Ethics approval and consent to participate}

The study was conducted in accordance with the Declaration of Helsinki including all amendments, and was approved by the Ethics Committee of Hospital Universitario 12 de Octubre (Madrid, Spain) as ethical reference committee. All patients gave written informed consent before their inclusion in the study, and their treatment followed routine clinical guidelines. All sites involved approved the study by their ethics committee (see list of sites in additional file 1).

\section{Consent for publication}

Not applicable.

\section{Competing interests}

ARA, LMP, MEJ, JBG, DLB and FGV have received a speaker or consultant fee from Janssen, Astellas and Bayer. They do not present a conflict of interest specifically for the realization of this article.

JMT and AGG are employees of Janssen Cilag-Spain.

\section{Author details}

'Urology Department, Hospital Universitario 12 de Octubre, Madrid, Spain.

${ }^{2}$ Urology Department, Hospital Universitario La Paz, Madrid, Spain. ${ }^{3}$ Urology Department, Hospital Universitario de Puerto Real, Cádiz, Spain. ${ }^{4}$ Urology Department, Complejo Hospitalario Universitario de Huelva, Huelva, Spain. ${ }^{5}$ Urology Department, Complejo Hospitalario Universitario de Orense, Orense, Spain. ${ }^{6}$ Janssen Medical Department, Paseo de las 12 estrellas 5-7, 28042 Madrid, Spain. ${ }^{7}$ Urology Department, Hospital Clínico Universitario de Salamanca e Instituto de investigación Biomédica de Salamanca (GITUR-IBSAL), Salamanca, Spain.

Received: 10 April 2019 Accepted: 25 September 2019

Published online: 16 October 2019

\section{References}

1. Arnold M, Karim-Kos HE, Coebergh JW, Byrnes G, Antilla A, Ferlay J, et al. Recent trends in incidence of five common cancers in 26 European countries since 1988 analysis of the European Cancer observatory. Eur J Cancer. 2015;51.

2. Siegel RL, Miller KD, Jemal A. Cancer statistics, 2017. CA Cancer J Clin. 2017;67(1).

3. Mohler JL, Armstrong AJ, Bahnson RR, D'Amico AV, Davis BJ, Eastham JA, et al. Prostate Cancer, Version 1.2016. J Natl Compr Canc Netw. 2016;14(1).

4. Berger AM, Mooney K, Alvarez-Perez A, Breitbart WS, Carpenter KM, Cella D, et al. Cancer-Related Fatigue, Version 2.2015. J Natl Compr Canc Netw. 2015;13(8).

5. Colloca G, Venturino A, Governato I, Checcaglini F. Incidence and Correlates of Fatigue in Metastatic Castration-Resistant Prostate Cancer. A Systematic Review. Clin Genitourin Cancer. 2016, 14;(1).

6. Lindqvist $\mathrm{O}$, Rasmussen $\mathrm{BH}$, Widmark $\mathrm{A}$. Experiences of symptoms in men with hormone refractory prostate cancer and skeletal metastases. Eur $J$ Oncol Nurs. 2008:12, 4

7. Engl T, Drescher D, Bickeboller R, Grabhorn R. Fatigue, depression, and quality of life in patients with prostatic diseases. Cent European J Urol. 2017:70(1).

8. Ritch CR, Cookson MS. Advances in the management of castration resistant. prostate cancer. BMJ. 201617.

9. Rawlinson A, Mohammed A, Beatty J, Bell R, Miller M. The role of abiraterone in the management of metastatic castration-resistant prostate cancer. Expert Rev Anticancer Ther. 2012;12(4)

10. Sternberg CN, Molina A, North S, Mainwaring P, Fizazi K, Hao Y, et al. Effect of abiraterone acetate on fatigue in patients with metastatic castration-resistant prostate cancer after docetaxel chemotherapy. Ann Oncol. 2013;24(4).
11. Prue G, Rankin J, Allen J, Gracey J, Cramp F. Cancer-related fatigue: A critical appraisal. Eur J Cancer. 2006:42(7).

12. Mendoza TR, Wang XS, Cleeland CS, Morrissey M, Johnson BA, Wendt JK, et al. The rapid assessment of fatigue severity in cancer patients: use of the Brief Fatigue Inventory. Cancer. 1999;85(5).

13. Esper P, Mo F, Chodak G, Sinner M, Cella D, Pienta KJ. Measuring quality of life in men with prostate cancer using the functional assessment of cancer therapy-prostate instrument. Urology. 1997;50(6).

14. Landis JR, Koch GG. The measurement of observer agreement for categorical data. Biometrics. 1977;33(1).

15. Yennurajalingam S, Atkinson B, Masterson J, Hui D, Urbauer D, Tu SM, et al. The impact of an outpatient palliative care consultation on symptom burden in advanced prostate cancer patients. J Palliat Med. 2012;15(1).

16. Curt GA, Breitbart W, Cella D, Groopman JE, Horning SJ, Itri LM, et al. Impact of cancer-related fatigue on the lives of patients: new findings from the Fatigue Coalition. Oncologist. 2000;5(5)

17. Basch E, lasonos A, McDonough T, Barz A, Culkin A, Kris MG, et al. Patient versus clinician symptom reporting using the National Cancer Institute Common Terminology Criteria for Adverse Events: results of a questionnaire-based study. Lancet Oncol. 2006;7(11).

18. Vogelzang NJ, Breitbart W, Cella D, Curt GA, Groopman JE, Horning SJ, et al. Patient, caregiver, and oncologist perceptions of cancer-related fatigue: results of a tripart assessment survey. The Fatigue Coalition. Semin Hematol. 1997:34(3 Suppl 2).

19. Williams LA, Bohac C, Hunter S, Cella D. Patient and health care provider perceptions of cancer-related fatique and pain. Support Care Cancer. 2016:24(10).

20. Teunissen SC, Wesker W, Kruitwagen C, de Haes HC, Voest EE, de Graeff A. Symptom prevalence in patients with incurable cancer: a systematic review. J Pain Symptom Manage. 2007;34(1).

21. Farkkila N, Torvinen S, Roine RP, Sintonen H, Hanninen J, Taari K, et al. Health-related quality of life among breast, prostate, and colorectal cancer patients with end-stage disease. Qual Life Res. 2014;23(4).

22. Gupta D, Braun DP, Staren ED. Prognostic value of changes in quality of life scores in prostate cancer. BMC Urol. 2013;13:32.

23. Thiery-Vuillemin A, Poulsen MH, Lagneau E, Ploussard G, Birtle A, Dourthe $L M$, et al. Impact of abiraterone acetate plus prednisone or enzalutamide on fatigue and cognition in patients with metastatic castration-resistant prostate cancer: initial results from the observational AQUARiUS study. ESMO open. 2018:3(5)

\section{Publisher's Note}

Springer Nature remains neutral with regard to jurisdictional claims in published maps and institutional affiliations.

Ready to submit your research? Choose BMC and benefit from:

- fast, convenient online submission

- thorough peer review by experienced researchers in your field

- rapid publication on acceptance

- support for research data, including large and complex data types

- gold Open Access which fosters wider collaboration and increased citations

- maximum visibility for your research: over $100 \mathrm{M}$ website views per year

At BMC, research is always in progress.

Learn more biomedcentral.com/submissions 